\title{
DO SCHÜLER-ZEITUNG AO O ATENEU: MARCAS DA CULTURA ESCOLAR NAS PÁGINAS DOS PERIÓDICOS (SÃO LEOPOLDO/RS, 1964-1973)
}

\author{
Luciane Sgarbi Santos Grazziotin \\ Universidade do Vale do Rio dos Sinos, Brasil. \\ Joana Frank \\ Universidade do Vale do Rio dos Sinos, Brasil.
}

\section{$\cos 80$}

\begin{abstract}
Resumo
O trabalho investiga o periódico O Ateneu, produzido pelos alunos de uma escola de São Leopoldo/RS, entre os anos de 1937 e 1973. O recorte escolhido foi as décadas de 1964 a 1973. A investigação de propôs a analisar os discursos referentes ao contexto da ditadura militar no Brasil. O Ateneu é tomado como um elemento da cultura material escolar que representa a possibilidade de tangenciar alguns aspectos referentes à cultura escolar de uma instituição de confissão luterana, representativa da Região do Vale do Rio dos Sinos. Observa-se que $O$ Ateneu foi um espaço de afirmação e construções identitárias de um grupo de jovens estudantes secundaristas. Quanto aos discursos relativos ao regime ditatorial, percebe-se que as manifestações presentes no periódico aparecem, em sua maioria, de forma velada. No entanto, também é possível entender que os estudantes preocupavam-se com as questões sociais e políticas do país, pois, no ano de 1963, há registros de que nessa escola formou-se o Departamento de Estudos Políticos e Sociais Brasileiros - DEPSB - como órgão do Grêmio Estudantil. Nos registros do caderno de atas do DEPSB não só alunos, mas também um professor se reuniam normalmente no turno da noite para debater o que eles registraram como sendo temas atuais da política brasileira e internacional.

Palavras-chave: cultura escolar, periódicos estudantis, memória, ditadura militar.
\end{abstract}

\section{THE SCHÜLER-ZEITUNG AO THE ATHENAEUM: MARKS SCHOOL OF CULTURE ON PAGES OF PERIODICALS (SÃO LEOPOLDO/RS, 1964-1973)}

\section{Abstract}

The work investigates the journal The Athenaeum, produced by students of a schooling São Leopoldo/RS, between the years 1937 and 1973. The clipping wash o sent the decades from 1964 
to 1973. The research proposed to analyze the discourses present related to the context of the military dictator ship in Brazil. The Athenaeum is taken as an element of material culture school that represents the tangent possibility of some aspects of the school culture of Lutheran confession representative of Vale do Rio dos Sinos. Observe that The Athenaeum was a space of affirmation and identity constructions of a group of young high school students. As for speeches concerning the dictatorial regime, it is observed that the present manifestations appearing the journal, mostly covertly. However, it is also possible to understand through research, that students were concerned with the social and political issues of the country because, in 1963, there are records of this school that graduated from the Department of Political and Social Studies Brazilians - DEPSB as an organ of student guild. In the records of the minutes of the tender DEPSB, not only students but also a teacher usually met on the night shift to discuss what they recorded as current issues of international and brazilian politics.

Key-words: culture school, journal student, memory, military dictatorship.

\title{
EL SCHÜLER-ZEITUNG AO EL ATENEO, MARCASDE LA CULTURA DE LA ESCUELA EN LAS PÁGINAS DE PUBLICACIONES PERIÓDICAS (SÃO LEOPOLDO/RS, 1964-1973)
}

\begin{abstract}
Resumen
El trabajo investiga la revista El Ateneo, elaborado por estudiantes de una escuela en São Leopoldo/RS, entre los años 1937y 1973. El recorte fue elegido para las décadas 1964 a 1973. La investigación se propone analizarlos discursos relacionados con el contexto de la dictadura militar en Brasil. El Ateneo se toma como un elemento de la cultura material escolar que representa la posibilidad tangente de algunos aspectos dela cultura escolar de una institución de Confesión Luterana representante de Vale do Rio dos Sinos. Observe que El Ateneo era un espacio de construcción y afirmación de la identidad de un grupo de jóvenes estudiantes de secundaria. En cuanto a los discursos sobre régimen dictatorial, se observa que las manifestaciones actuales aparecen en la revista, en su mayoría clandestinamente. Sin embargo, también es posible entender que los estudiantes estaban preocupados por los problemas sociales y políticos del país, ya que, en 1963, existen registros de esta escuela que se graduó en el Departamento de Estudios Brasileños Políticas y Sociales - DEPSB - como órgano del Sindicato de Estudiantes. En los registros de las actas de la DEPSB licitación, no sólo a estudiantes sino también un maestro por lo general se reunieron en el turno de noche para discutir lo que registra como temas de actualidad de la política internacional y brasileña.

Palabras-clave: cultura escolar, gaceta de estudiantes, memoria, régimen dictatorial.
\end{abstract}

\section{DE SCHÜLER-ZEITUNG À O ATENEU: MARQUES DE LA CULTURE SCOLAIRE DANS LES PAGES DU PERIODIQUE (SÃO LEOPOLDO/RS, 1964-1973)}

\section{Résume}

La recherche explore le périodique L'Athénée, realisé par des élèves d'une école de São Leopoldo/RS pendant les anées de 1937 et 1973. Le periode choisi a été dans les décades de 1964 à 1973. La recherche analyse les discours qui se repportent au contexte de la dictature militaire au Brèsil. O Ateneu est consideré comme un élément da la culture scolaire de l'école qui represente la possibilité d'observer les aspects relatifs à la culture scolaire d'une école lutherienne au Vale do Rio dos Sinos. On observe que L'Athénée a été un espace de construction de l'identité d'un groupe de jeunes étudiants du secondaire. Dans le qui concerne au régime de la dictature de cette époque-lá, on observe que les manifestations sont discrètes. Pourtant, est aussi possible de comprendre par la recherche que les étudiants ont étaient interessés par les questions sociales et politiques du pays, ainsi que, en 1963, dans cette école, il y avait la fondation du Departamento de Estudos Políticos e Brasileiros - DEPSB -, comme un departement du Grêmio Estudantil. Dans les enregistrements du DEPSB, non seulement les étudiantes mais aussi un einseignant, 
habituellement se rencontraient dans le period de la nuit pour discuter ce qu'ils ont enregistré comme thémes d'actualité de la politique brèsilienne et international.

Mots-clé: culture scolaire,periodiques des étudiants, mémoire, dictature militaire.

\section{Introdução}

- ssa pesquisa trabalha com documentos pertencentes a acervos escolares e faz parte de um projeto de maior amplitude intitulado Cultura escolar, memória e cultura material: interfaces entre aspectos históricos e políticas públicas instituídas entre 1930 a 1996.

A investigação tem sua centralidade na análise de artefatos da cultura material de seis instituições educacionais, cinco de Porto Alegre e uma de São Leopoldo, o Colégio Sinodal. Nesse artigo, especificamente, analisa-se de forma preliminar o periódico $O$ Ateneu, jornal escrito pelos alunos do Colégio Sinodal de São Leopoldo. Os documentos encontram-se no acervo da referida instituição.

A memória de uma instituição escolar, seus rituais, pertenças religiosas e culturais, seus objetos, formas de produzir e utilizar os espaços e entender os tempos escolares está presente em diferentes documentos que podem ser analisados e estudados, com vistas a contar uma história que permita compreender o processo de educação em um tempo e lugar.

A utilização de objetos da cultura material fazem parte do repertório documental utilizado por pesquisadores de História da Educação, como forma de compreender alguns elementos que compõem a cultura escolar ${ }^{1}$. A cultura material é entendida, segundo Meneses, como "todo segmento do universo físico socialmente apropriado", onde os artefatos compreendem um dos componentes mais importantes $(2005$, p. 1). Segundo Souza (2007), esse conjunto pode ser pesquisado a partir de dois enfoques temáticos: a história das instituições educativas e a história da leitura e da escrita. Desse último emergem os livros de leitura e de literatura infanto-juvenil, cartilhas, programas de ensino, cadernos, manuais didáticos, periódicos com finalidade pedagógica "e toda uma diversidade de impressos, ou seja, suportes materiais da escrita e da leitura e de difusão e circulação de idéias." (Ibid., p. 172).

Entre esses elementos da cultura material, a utilização de periódicos escolares escritos por alunos como fonte documental é uma opção no sentido de tentar perceber aspectos de uma cultura escolar que se manifesta a partir das representações dos estudantes no contexto escolar. Embora esse seja um estudo inicial e a análise de um periódico represente um pequeno fragmento no universo da cultura escolar, Magalhães (2010) afirma que "a educação e o educacional não foram totalidade histórica, mas o sentido que verdadeiramente lhes corresponde fica inscrito no interior de uma

\footnotetext{
${ }^{1}$ Cultura escolar é entendida como "um conjunto de normas que definem conhecimentos a ensinar e condutas a inculcar, e um conjunto de práticas que permitem a transmissão desses conhecimentos e a incorporação desses comportamentos; normas e práticas coordenadas a finalidades que podem variar segundo as épocas finalidade religiosa, sociopolítica ou simplesmente de socialização" (Julia, 2001, p. 12).
} 
historiografia do total" (p. 17). É na direção de inscrever as práticas estudantis e as apropriações por parte desses dos diferentes aspectos que compõem o processo de escolarização que o estudo de periódicos torna-se significativo para a História da Educação.

\section{Percurso da pesquisa}

Como o historiador da educação chega a um documento? Essa é uma pergunta freqüente quando deparamo-nos com pesquisas cujas fontes, em um primeiro momento, nos encantam. É também uma espécie de encantamento que acomete cada pesquisador, que tem nos documentos seu instrumento de investigação e encontra algo inusitado. Embora o exercício de desencantá-las e problematizá-las seja fundamental no decorrer de uma pesquisa, o primeiro momento de entusiasmo é fundamental para a empreitada de mergulhar em papéis, em memórias, em objetos, em fotografias, entre tantas possibilidades que servirão de fontes a serem interrogadas.

O estudo com o periódico estudantil O Ateneu teve início no decorrer do primeiro semestre de 2012, junto à disciplina de História da Educação, ministrada para o curso de Pedagogia.

O trabalho proposto para a turma tinha cunho prático e teórico. Pediu-se que cada estudante trouxesse um artefato: objetos, livros, atas, atestados, históricos escolares, memórias orais de ex-professoras ou alunas, fotografias, enfim, elementos escolares que pudessem ser analisados, que pudessem se transformar em documento e subsídio para a disciplina de História da Educação. O material trazido seria separado, catalogado, analisado e cada estudante escreveria um ensaio, tendo o documento escolhido como fonte. Nesse processo, uma estudante questionou sobre a validade de um jornal como documento, se esse poderia ser utilizado na proposta a ser desenvolvida. Coincidentemente, o periódico ao qual ela se referia fazia parte o acervo de uma das escolas que compõem o universo empírico do projeto de pesquisa ao qual desenvolvo junto ao Programa de Pós-Graduação em Educação da Universidade do Vale Rio dos Sinos e que, no entanto, desconhecia até o momento.

O contato com o periódico foi uma grata surpresa, uma vez que apresentou diferentes elementos que contam sobre um processo de circulação de idéias e ideais, de formas de perceber a educação em um contexto cujo pertencimento religioso e cultural marca a cultura escolar de uma época e lugar.

São esses casos, obras do acaso, do imponderável, como diz Cunha (2012), que propiciou a união entre um trabalho que eu já havia realizado e uma aluna de graduação, que se depara com esse artefato na escola em que trabalha.

A fonte principal desse estudo são os periódicos Schüler-Beitung e O Ateneu, bem como a análise dos registros do caderno de atas do Departamento de Estudos Políticos e Sociais Brasileiros - DEPSB -, resultantes das reuniões dos alunos e de um professor que os acompanhava.

Tânia Regina de Luca (2007) analisa o processo historiográfico dessa reconhecida fonte documental. Segunda ela "na década de 1970 ainda era relativamente pequeno o número de trabalhos que se valia de jornais e revistas como fonte" (p. 111). Atualmente, em virtude de correntes historiográficas, como a história cultural, esse artefato, antes 
considerado somente como veículo de propagação de notícias, tornou-se valioso no processo de produzir História.

$\mathrm{Na}$ utilização de periódicos como documento é importante estar alerta à sua materialidade e seus suportes que nada tem de natural: "historicizar a fonte requer ter em conta as condições técnicas de produção e a averiguação do que se dispunha, do que foi escolhido e por quê" (Luca, 2007, p. 132). Nessa investigação fez-se um exercício de tentar entender a função que esse impresso desempenhou no contexto do Colégio Sinodal, na década de 1970, com relação às questões políticas e sociais que envolviam o país.

Os periódicos aqui trabalhados são o Schüler-Beitung, as edições do mês de abril de 1938, e O Ateneu, do n. 183, de março/abril de 1964, ao n. 251, de junho de 1973. Com esse recorte temporal optou-se, nesse primeiro momento, em identificar as possíveis marcas da política nacional, presentes ou não, nas páginas do $O$ Ateneu, bem como analisar as distintas apropriações discentes registradas em suas páginas.

A análise remete a uma série de perguntas no sentido de entender como esses estudantes se apropriavam dos discursos políticos e do processo social ao qual o país estava vivendo? As páginas d'O Ateneu chegaram a ser um espaço de reivindicação ou de manifestação de descontentamento ou não com a situação política do país? Houve alguma influência do momento histórico nas edições do jornal?

\section{Uma retomada histórica: o Schüler-Beitung e 0 Ateneu, memórias de uma escola}

A cidade de São Leopoldo, localizada na região metropolitana de Porto Alegre, é conhecida como o berço da colonização alemã no Rio Grande do Sul. Em 1824, ao chegarem ao Brasil, os alemães cultivaram seus hábitos: idioma, cultura e religião, em sua grande maioria luterana. O Sínodo Rio-Grandense ${ }^{2}$ foi o responsável, em grande medida, pela educação da região. Reuniu pequenas escolas de modo a melhorar as condições de estudo dos colonos que, conforme Kunert, "se fazia cada vez mais necessária uma instituição adequada para uma formação específica, uma escola de grande porte" (2011, p. 145).

Após inúmeras reuniões e deliberações, decidiu-se construir a tão sonhada escola, obedecendo às mudanças realizadas no setor educacional desde o início do Estado Novo. Getúlio Vargas, que governava desde 1930, impunha o nacionalismo, buscando o mais puro espírito brasileiro em todas as instituições e impedindo que colonos se comunicassem ou lecionassem em sua língua materna. Neste contexto é lançada, em 1936, a pedra fundamental do Colégio Sinodal.

Assim como o Estado Novo, os diferentes contextos políticos brasileiro influenciaram a conjuntura educacional do país. Foi o caso da ditadura civil/militar, que produziu efeitos nas diferentes instituições de ensino em todo o território nacional. As marcas dos diferentes contextos de ordem política, econômica, social e cultural, bem como seus

\footnotetext{
${ }^{2}$ O Sínodo Rio-grandense é o precursor da atual Igreja Evangélica de Confissão Luterana no Brasil IECLB. Foi fundado em 20 de maio de 1886, em São Leopoldo/RS, o com a presença de sete pastores e sete delegados leigos que representavam sete comunidades: São Leopoldo, São Sebastião do Caí, Santa Cruz do Sul, Igrejinha, Santa Maria, Dois Irmãos e Teutônia
} 
efeitos nas instituições escolares e na educação do país podem ser identificados, traduzidos e analisados a partir dos acervos documentais encontrados em distintas instituições de ensino.

Trabalhar com esses acervos tem sido, no percurso que venho trilhando, uma constante surpresa com relação às fontes documentais encontradas. Em cada instituição as características dos acervos apresentam-se singulares; é um universo de outro tempo que instiga o pesquisador. As perguntas feitas a priori, no momento do projeto de pesquisa, por vezes perdem o sentido, pois a materialidade dos objetos encontrados apontam para outras possibilidades historiográficas que não correspondem, em muitos casos, às primeiras interrogações. Cada espaço documental manifesta idiossincrasias e traz possibilidades de análises específicas que, paradoxalmente, de forma simultânea, podem conferir possibilidades totalizantes, comuns a determinada época.

O contato com o acervo do Colégio Sinodal de São Leopoldo não foi diferente. Essa instituição tem em sua trajetória a marca da preservação da memória. Essa afirmação baseia-se em diferentes elementos: além do fato de ter um museu e um acervo ${ }^{3}$ organizado, que por si são marcas da valorização da memória da escola, ainda conta com a publicação de três livros que tem a função de revigorar os processos de manutenção e fortalecimento identitários. A escola, há setenta e seis anos, caracteriza a educação luterana, não só no Vale do Rio dos Sinos, mas no Rio Grande do Sul (Fischer, 2011). Nesse contexto, chama atenção a organização da documentação, em especial com relação ao arranjo das edições do periódico trabalhado. Os periódicos se encontram rigorosamente organizados por data e as edições encadernadas, sendo que as primeiras, manuscritas, quando ainda se chamava Schüler-Beitung. São preciosidades guardadas no cofre da instituição.

O jornal escolar, que nasceu praticamente junto com a instituição de ensino luterana, se constituiu em iniciativa dos alunos um ano após o início oficial de seu primeiro ano letivo em 1937. A primeira edição é de 11 de abril de 1938, cujo o nome era SchülerBeitung, que significa Jornal Estudantil/Escolar. Observou-se, com essa denominação, mais duas tiragens em 21 e 29 de abril do mesmo ano. Devido ao número ainda pequeno de alunos, o jornal não era impresso, mas manuscrito. Da primeira edição foram distribuídos apenas quatro exemplares e, no total, foram apenas três edições.

O Schüler-Beitung era escrito basicamente em alemão, porém possuía uma estrutura muito parecida com a do seu sucessor, O Ateneu. Trazia temas atuais, acontecimentos de dentro do colégio, gafes de alunos e professores, entre outros elementos que compunham suas páginas.

As três primeiras edições, todas do mês de abril, foram escritas em folhas de linha azul, provenientes de folhas de caderno. O nome Schüler-Beitung encontrava-se no alto da página e era a única seção que não era manuscrita, vinha marcada com uma espécie de carimbo. Imagens esparsas são percebidas e todas têm a mesma característica: temse a impressão que foram carimbadas, eventualmente encontra-se algum desenho. A análise de suas páginas nos possibilita inferir que o periódico teve início como um exercício proposto em alguma disciplina.

\footnotetext{
${ }^{3} \mathrm{O}$ acervo do Colégio Sinodal de São Leopoldo foi organizado pela professora Lilian Sofia Saenger.
} 
Figura 1

Terceira edição do Schüler-Beitung.

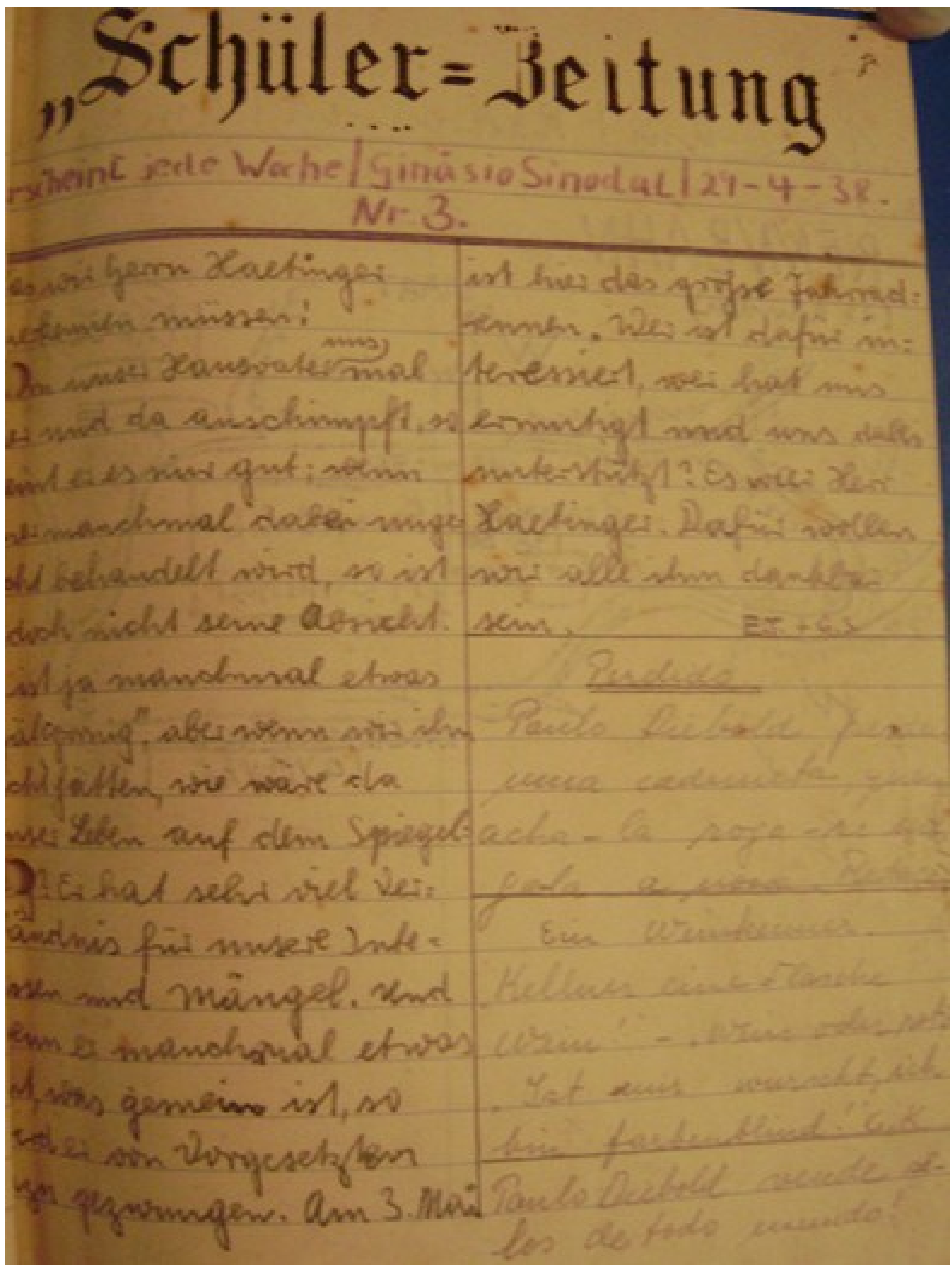

Fonte: Acervo Colégio Sinodal. 
Em 1939 o interesse com relação ao periódico escolar cresceu e o grêmio estudantil, que recebia o nome de Tobias Barreto, liderou uma campanha para os alunos a sugerissem nomes para um jornal oficial dos alunos do Colégio Sinodal. Os nomes que marcaram a competição foram: 0 Ateneu ${ }^{4}$ e Hermes. Decidiu-se que seria utilizada a nomenclatura $O$ Ateneu, pelo fato de o nome Hermes fazer também alusão ao Deus dos bandidos.

Assim, em julho de 1939 encontra-se a publicação já com o nome de O Ateneu. As três primeiras edições, correspondentes aos meses de julho, agosto e setembro de 1939, são mimeografadas pelos editores-alunos. Com dificuldades em obter um bom resultado, a direção do Colégio aceitou dividir as despesas para que o periódico pudesse ser impresso por terceiros. A partir da edição de outubro do ano de 1939 ,o jornal passou a ser impresso pela Editora Rottermund.

Quadro 1

Freqüência das publicações entre 1938 e 1940.

\begin{tabular}{|c|c|c|}
\hline Nome do periódico & Temporalidade & Forma de impressão \\
\hline Schüler-Beitung & $11 / 4 / 1938$ & Folha de caderno \\
\hline Schüler-Beitung & $21 / 4 / 1938$ & Folha de caderno \\
\hline Schüler-Beitung & $29 / 4 / 1938$ & Folha de caderno \\
\hline O Ateneu & $7 / 1939$ & Folha mimeografada \\
\hline O Ateneu & $8 / 1939$ & Folha mimeografada \\
\hline O Ateneu & $9 / 1939$ & Folha mimeografada \\
\hline O Ateneu & $10 / 1939$ & Impresso Ed. Rottermund \\
\hline O Ateneu & $11 / 1939$ & Impresso Ed. Rottermund \\
\hline O Ateneu & $12 / 1939$ & Não houve tiragem \\
\hline O Ateneu & $1 / 1940$ & Não houve tiragem \\
\hline O Ateneu & $2 / 1940$ & Não houve tiragem \\
\hline O Ateneu & $3 / 1940$ & Impresso Ed. Rottermund \\
\hline
\end{tabular}

Em março de 1940 ,em função da Segunda Guerra Mundial, a publicação do jornal foi interrompida. Foi retornada em março de 1945 com a seguinte afirmação:

\begin{abstract}
Ressurge "O Ateneu". Com quanta satisfação recebemos, professores e alunos, este acontecimento! Concretiza-se, assim, uma aspiração antiga de todos. Digase, de passagem, ressurgiu agora registrado oficialmente no DIP sob o número 14676. "O Ateneu" já tem sua historia. A comunidade sofreu. Quando as autoridades submeteram a imprensa, e mesmo a do nosso gênero, a dispendioso processo de registro, desanimamos. Agora que nossa co-irma a Fundação Evangélica, é oficializada dobrou-se a impetuosidade do velho desejo e, conseqüentemente, o nosso ânimo. Será "O Ateneu órgão de dois estabelecimentos irmanados pelos mesmos ideais. (O Ateneu, mar., 1945, p.1)
\end{abstract}

\footnotetext{
${ }^{4}$ Ateneu foi um escritor da Grécia antiga. É conhecido pela coleção de quinze obras intituladas de Deipnosofistas - $\mathrm{O}$ banquete dos deuses.
} 
Observa-se, com essa introdução, a importância que era atribuída ao periódico com relação à exaltação do caráter comunitário identificado com a doutrina Luterana da IECLB.

Quanto à periodicidade, houve variação ao longo do tempo. No ano de 1945 foi impresso mensalmente. Nos anos posteriores, suas edições passaram a ser espaçadas. Na década de 1980 as publicações eram trimestrais.

$\mathrm{Na}$ medida em que os alunos deixaram de se interessar e de mandar artigos e matérias para a equipe de edição, curiosamente, na mesma época em que a ditadura aumentava sua repressão, as edições espaçavam-se, chegando a intervalos de até quatro meses.

Faziam parte da maioria das edições as seguintes seções: Crônicas, na qual se contavam os acontecimentos dos últimos meses; textos em língua estrangeira: inglês, alemão, espanhol ou francês; Aconteceu, que trazia ao público as maiores gafes de alunos, de professores e, sempre na primeira edição, a lista daqueles que prestaram ou foram aprovados no vestibular.

\section{A memória social presente nas páginas do Schüler-Beitung e d'O Ateneu}

O contato com esses dois impressos estudantis permite, em certa medida, identificar a trajetória política da sociedade brasileira no período estudado. Se, no início, o SchülerBeitung era um jornal que pode ser considerado singelo, porque escrito em folhas de caderno, com assuntos corriqueiros, piadas, contos e notícias domésticas, características de algo que está principiando, com decorrer do tempo observa-se preocupação com o contexto social. Sendo assim, sua análise possibilita a historicização de uma sociedade e, mesmo em um nível micro, permite reflexões globalizantes com características que, em contexto nacional, tem representatividade para o entendimento de um tempo.

Nesse sentido, analisando-se o processo de escrita pelo qual passaram os dois jornais, é possível perceber que se inicia com o título e a escrita em alemão e, em 1939, na sua terceira publicação, já ocorre a mudança de nomenclatura e passa a se chamar $O$ Ateneu, cuja redação é realizada em português. Essa alteração coincide com o Estado Novo e a proibição da utilização de outra língua que não o português, sobretudo em comunidades de colonização alemãs e italianas, como é o caso da região Sul do país.

Seguindo os rastros das modificações do jornal, é sabido que no de 1964 o contexto político brasileiro mudou com a deposição do presidente João Goulart e a tomada do governo pelas Forças Armadas. Para os militares, qualquer cidadão que se opusesse aos seus ideais era considerado inimigo. De imediato, inúmeros partidos foram fechados, políticos da oposição presos e, à medida que os anos passavam, o regime se tornava mais violento. Os estudantes, que eram alguns dos cidadãos mais ativos politicamente na época, viram sua liberdade ser delimitada com o fechamento da União Nacional de Estudantes - UNE. Oficialmente, quaisquer reuniões, encontros ou mesmo conversas relacionadas à política de oposição eram repreendidas.

Esse panorama é evidenciado em inúmeras obras de pesquisadores que estudamos anos da ditadura militar no Brasil. No entanto, pode-se perguntar se os meios estudantis de todo o pais comportaram-se da mesma maneira. 
As formas dos estudantes secundaristas se manifestarem, nas diferentes regiões do país, não foram às mesmas. Bortod (2008) descreve as manifestações estudantis nas metrópoles do centro do país e nas capitais e afirmando que a indignação entre eles era grande, porém mesmo sabendo que poderiam ser presos, os estudantes continuavam a se reunir com os membros da UNE na busca de soluções para o problema em que se encontravam.

Para os alunos dos colegiais, que na sua maioria ainda eram menores de idade, participar de tais manifestações era mais complicado, porém não impossível. Grêmios estudantis, periódicos escolares e mesmo o contato com alguns professores aproximava os adolescentes das questões políticas (Bortod, 2008).

Entre as perguntas que norteiam essa pesquisa podemos pensar: em que medida um periódico estudantil se posiciona com relação ao contexto político do país? Quais foram as formas de manifestações encontradas no periódico O Ateneu? Quais as marcas deixadas pelos estudantes secundaristas do Colégio Sinodal com relação à ditadura militar no Brasil? Havia manifestações explicitas ou de maneira sutil?

Identifica-se, no ano de 1963, registros de que nessa escola os estudantes preocupavam-se com as questões sociais e políticas do país. Meses antes do início período ditatorial, formou-se no Colégio Sinodal o Departamento de Estudos Políticos e Sociais Brasileiros - DEPSB - como órgão do Grêmio Estudantil. Nos registros do caderno de atas do DEPSB, não só alunos, mas também um professor se reuniam no turno da noite para debater temas atuais da política brasileira e internacional. No livro de atas aparecem poucos apontamentos dos assuntos debatidos. Na maioria dos casos, são apenas descritos os participantes, a duração da reunião e alguns dados técnicos. A discrição, deduz-se, era a melhor amiga de quem não podia se expor. As reuniões continuaram acontecendo e sendo registradas até meados da década de 1970.

O recorte a seguir, edição n. 183 de março/abril de 1964, esclarece no que consiste o Departamento de Estudos Políticos e Sociais Brasileiros e indica que, no ano de 1964, devido as agitação pela qual passava o país, a diretoria suspendeu os trabalhos do departamento. 


\section{Figura 2}

Esclarecimento acerca do DEPSB.

\section{ESCLARECIMENTO}

O DEPSB é um órgão do Grêmio Cívico e Literário Tobias Barreto e visa possibilitar a todos os alunos do Colégio Sinodal o contato mais intimo e mais sāo possivel, através de debates e palestras, com os problemas nacionais, tanto politicos como sociais, tendo sempre presente o imperativo de orientar uma juventude mais politizada e orientada para um Brasil cada vêz mais democrático, livre e grande.

Esta missāo é definida no Art. I do regimento interno do Departamento, que fixa tambêm a orientação que o mesmo deverá seguir.

Entretanto, devido a agitaçāo pela qual passou o país, aos movimentos pós-revolucionários, evitando possiveis criticas inconvenientes, difusāo de boatos e mal entendidos, a diretoria do GT resolveu suspender os trabalhos temporàriamente, fleando a critério do Departamento qualquer realizacāo possivel. DEPSB

Fonte: O Ateneu, n. 183, mar., 1964. 
Em um recorte de 1966, números 198 e 199 de março/abril, na coluna Políticos e sociais, lê-se uma manifestação de preocupação com a formação de sujeitos informados sobre a realidade do país.

Figura 3

Coluna Políticos e sociais.

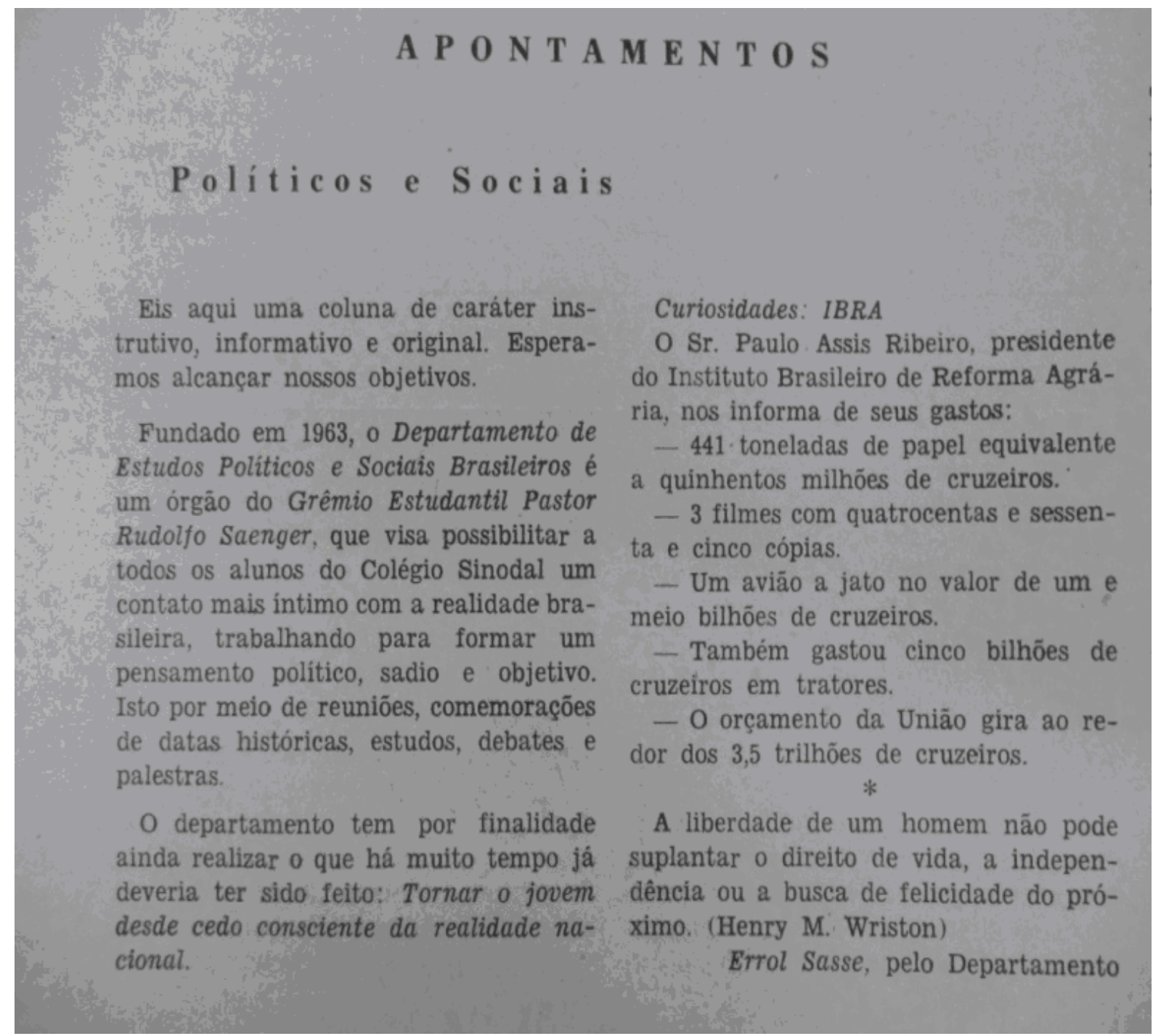

Fonte: O Ateneu, n. 198/199, mar./abr., 1966.

No ano de 1966, a edição n. 204 do mês de setembro e, no ano de 1967, as edições n. 210 do mês de maio e n. 211 de junho, apresentaram uma série de textos produzido por um aluno do $3^{\circ}$ ano, cujo tema versa sobre democracia. Os títulos são respectivamente: Democracia - um caminho difícil, Democracia - o imenso futuro do homem e Democracia - o sistema de vida democrático. Nesse último, observa-se a gravura escura em que delineia-se a imagem de um livro com uma vela a iluminá-lo. Lendo-se os três textos não se percebe uma única crítica direta à ditadura. No entanto, pode-se entender que a presença, em um periódico estudantil, de um assunto tão 
polêmico e controverso para a época quanto à democracia, pode ser considerada como uma crítica velada.

Em outras edições do periódico O Ateneu, n. 240/243, correspondente aos meses de março/junho de 1971, lê-se o seguinte: "O homem nos nossos dias é um estranho. Ouve, mas não escuta. Olha e não vê. Emite sons e não se comunica. Procura-se a autoafirmação em tudo menos no que realmente importa. E por quê? (Beys, 1971)". A reflexão segue uma linha de questionamentos sobre o que acontecia com o homem dos nossos dias.

É perceptível como uma pequena parcela dos colaboradores do jornal, por esse meio de comunicação que servia, em última análise, como suporte para circulação de suas idéias, empenhavam-se em chamar atenção dos colegas para a situação sociopolítica que se apresentava.

Seguidamente apareciam textos que comentavam a situação política de outros países, modelos de governo e temas pungentes para a época, como a guerra no Vietnã, mas a situação brasileira era pouco ou nada comentada. Em alguns casos apareciam artigos com viés de esclarecimento no sentido de informar o que era esse jornal. Nessa perspectiva, na edição de n. 236/239, de agosto/novembro de 1970, por exemplo, se lê abaixo do título, na capa do jornal, a seguinte frase: "Um jornal que não imita o Pasquim".". Após um ano, encontra-se o seguinte parágrafo, logo na primeira página:

O prezado veterano irá notar que este Ateneu está um pouco diferente dos que já saíram anteriormente, mas êle poderá constatar que é a procura de uma nova forma de jornalismo amador sinodalense. É claro que não seremos extremistas à la Pasquim, ou então conservadores como a Folha Dominical. Estamos procurando novas formas para que o distinto associado possa ter um jornal que acompanhe a evolução, não querendo isto significar que êste jornal seja um meio de massificação. Não dispomos de grandes jornalistas, temos, isto sim, gente que trabalha por não querer ser um simples parasita, ou seja, simplesmente existir. (O Ateneu, n. $240 / 243,1971$, p. 3$)^{6}$

O Pasquim foi um semanário que ficou nacionalmente conhecido por se opor abertamente à ditadura. Com um novo estilo de humor, trabalhava inicialmente assuntos como sexo, feminismo, drogas, mas à medida que a repressão aumentava, o tema principal se tornou a política brasileira. O Pasquim passou, então, a ser o porta-voz dos estudantes reprimidos, dos exilados políticos, entre tantos outros. Com isso em mente, os estudantes indicam, através do enunciado publicado, que condenam o extremismo do Pasquim, mas não estavam alienados ao que acontecia.

Em outra manifestação é perceptível uma analogia da ditadura com a escuridão, mesmo que subliminarmente. Na edição n. 227, de maio de 1970, o texto do aluno Antônio Kipper diz:

${ }^{5}$ O jornal O Pasquim foi publicado entre os anos de 1969 e 1991 e figurou no universo dos jornais alternativos de base filosófica existencialista. Pelo do humor, criticou paradigmas e enfrentou os tabus da moral vigente, suscitando escândalos e provocando reações apaixonadas. Divulgou no Brasil temáticas da contracultura e da busca de novos modos de percepção através das drogas. As entrevistas do Pasquim tornaram-se a tribuna livre das vozes de oposição ao regime, o espaço para a manifestação de intelectuais, artistas e políticos (Queiros, 2004).

${ }^{6}$ Optou-se em manter a grafia da época. 
Sem luz todos são iguais, notam-se apenas sombras [...] a luz foi feita para dar chance aos homens. Chance de progredir, Chance de elevar-se, seja em caráter, em disposição, em situação social. No escuro não se nota se a pessoa é rico ou pobre, se é sujo ou limpo [...] no escuro só há vultos procurando a si mesmos.

Nas décadas seguintes, não se observa no O Ateneu manifestações mais enfáticas com relação ao contexto político vivenciado.

O regime militar surpreendia cada vez mais estudantes. Em 1973 os casos de tortura já não eram mais secretos. Nesse ano foi lançada a última edição do $O$ Ateneu. $O$ editor se despediu de modo triste: dizia-se envelhecido e desapontado com a juventude, que preferia outras atividades ao invés enviar artigos para serem publicados e que não pensavam mais em algo socialmente relevante.

Já nos anos anteriores, os editores do periódico pediam que os alunos colaborassem mais com a escrita de reportagens, textos e outras contribuições. Mas, coincidência ou não, no auge da violência e da repressão a comunicação, pelo menos dentro do Colégio Sinodal, perdeu a sua voz.

Nos anos seguintes, O Ateneu segue sendo publicado, mas em novo formato: mais simples, com menos páginas e com menos artigos. 
Figura 4

O Ateneu, 1973.

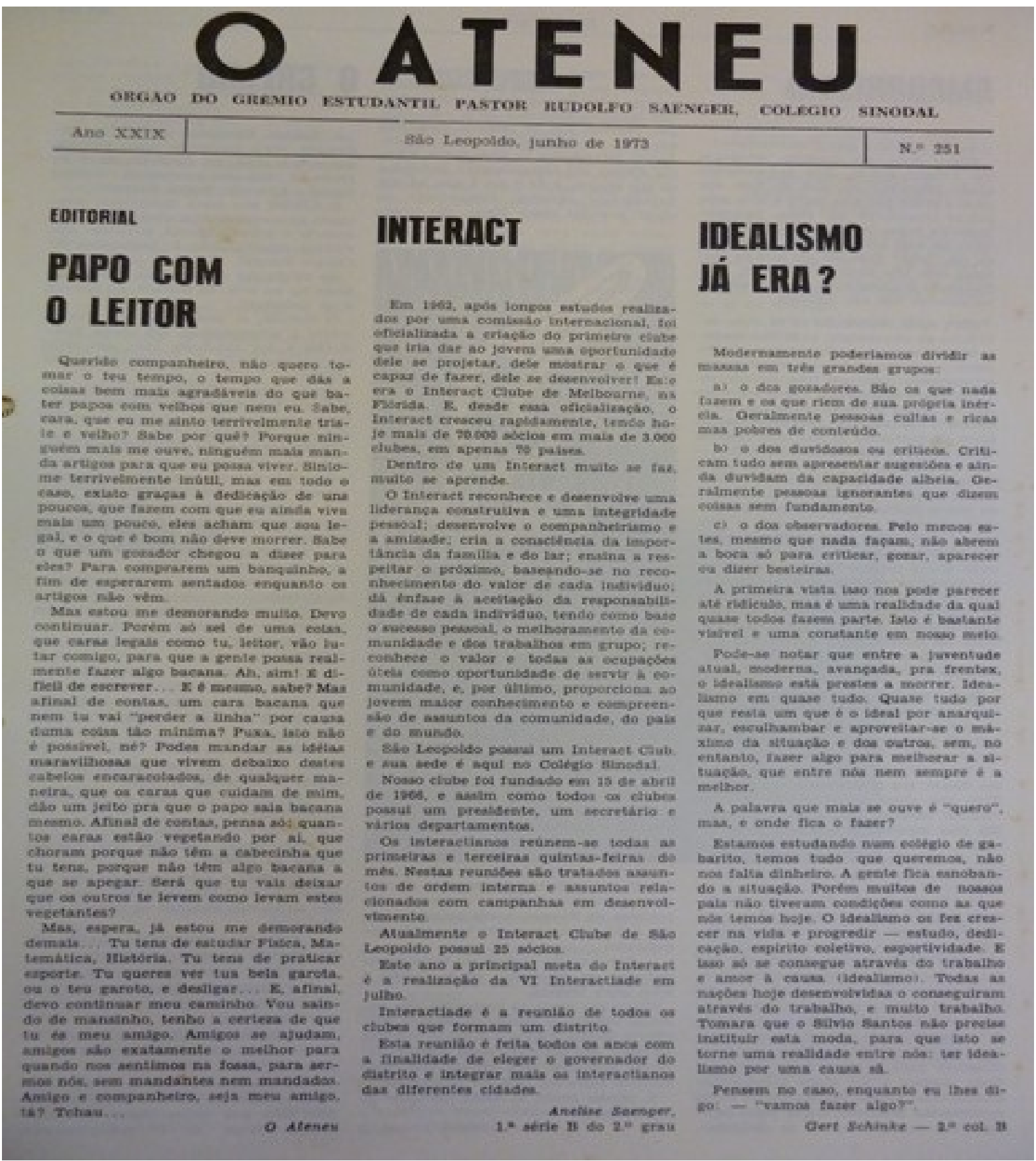

Fonte: O Ateneu, n. 251, jun., 1973.

\section{Considerações finais}

Esse estudo está em fase inicial e, portanto, a investigação de todo o conjunto de publicações não foi levado a termo. Apresentam-se aqui algumas considerações sobre os trinta e cinco anos analisados, dando-se ênfase aos discursos circulantes no jornal no que se refere ao contexto político, sobretudo aqueles referentes à ditadura civil/militar entre os anos de 1964 a 1973. 
O encontro com as singelas páginas do Schüler-Beitung remete a uma escola comprometida com sua identidade germânica fundante, em que as marcas da colonização teuto-brasileira estão presentes. O processo de transição para $O$ Ateneu pode ser percebido quando embrenhamo-nos na leitura dos periódicos cujos significados atribuídos pelo leitor podem traduzir as transformações políticas que marcaram a sociedade brasileira naquele período.

Ao folhear-se as páginas do O Ateneu deparamo-nos com um universo estudantil semelhante a outros já tematizados por Almeida (2011), como é o caso dos estudos realizados com o O Clarim, do Colégio Farroupilha, e O Crisol, do Colégio Americano. Essas pesquisas apontam para um universo juvenil e, além disso, "traduzem aspectos significativos do cotidiano escolar mostrando indícios de saberes e de práticas escolares identificadas a preceitos de civilidades" (Ibid., p. 8). No caso d'O Ateneu são nos discursos circulantes na escola, nas afinidades com determinada ideologia política, na religião professada, entre outros aspectos, que se percebe o cotidiano escolar de jovens estudantes. Esse se manifesta com suas singularidades relativas aos aspectos referentes à comunidade em que ela está inserida a escola. Também são identificadas características comuns vinculadas à um tempo e a determinada região. Bastos afirma que

a imprensa pedagógica - jornais, boletins, revistas, magazines, feita por professores para professores, feita para alunos por seus pares [...] contém e oferecem muitas perpecivas para a compreensão da história da educação e do ensino. Sua análise possibilita avaliar a política das organizações, as preocupações sociais, os antagonismos e filiações ideológicas, as práticas educativas. (1997, p. 49)

No encontro com os editoriais de O Ateneu há idícios de que os jovens dessa época tinham consciência do que acontecia e esse contexto social os incomodava. Os exertos retirados dos editoriais apresentam características que permitem essa afirmação. No entanto, algumas perguntas emergem no decorrer da invetigação: as contribuições eram feitas pelos próprios alunos, mas quantos coloboravam? Quem eram eles? Seriam sempre os mesmos a se envolver nesse processo? Em virtude dessas questões fica difícil falar em uma comunidade escolar comprometida com o retorno à democracia, no entanto, os textos trazem de forma sutil essa face de descontentamento.

Pode-se pensar se as manifestações, em sua maioria veladas, com relação ao contexto político do Brasil, repercutiram de alguma maneira na formação de uma geração de estudantes que participou na edição ou foi somente um leitor do jornal estudantil 0 Ateneu, publicação que, ainda com algumas interrupções e espaçamentos em suas tiragens, permanece até os dias de hoje sendo editado.

Mesmo não tendo elementos para fazer afirmações conclusivas com relação ao conteúdo específico do jornal, é fundamental refletir sobre o possível "processos de subjetivação provocado pelos textos escritos e suas possíveis influências nos modos como aqueles jovens pensavam, agiam e se expressavam nos espaços de construção de suas identidades" (Almeida, 2011, p. 12).

É plausível inferir, nessa análise ainda embrionária, que O Ateneu, entendido como um artefato da cultura material da escola foi, no período estudado, um "lugar de afirmação de um grupo e de permanente regulação coletiva" (Nóvoa, 1997, p. 13). 


\section{Referências}

ALMEIDA, Doris Bettencourt; LIMA, Valeska. Nas páginas do Clarim e do Crisol: um estudo sobre periódicos escolares (1940-1960). ENCONTRO DA ASSOCIAÇÃO SULRIO-GRANDENSE DE PESQUISADORES EM HISTÓRIA DA EDUCAÇÃO, 17, 2001, Santa Maria. Anais ... Santa Maria: Asphe, 2011.

BASTOS, Maria Helena Camara. As revistas pedagógicas e a atualização do professor: a Revista do Ensino do Rio Grande do Sul (1951-1992). In. CATANI, Denice Barbara; BASTOS, Maria Helena Camara. Educação em revista: a imprensa periódica e a história da educação. São Paulo: Escrituras, 1997, p. 47-75.

BEYS, Solange. Razões de sobra. In: O Ateneu, n. 240/243, 1971.

BORTOT, Ivanir José. Abaixo a repressão: movimento estudantil e as liberdades democráticas. Porto Alegre: Libretos, 2008.

BRASIL ESCOLA. <http://monografias.brasilescola.com/historia/ditadura-militar-no-brasil. htm>. Acesso em: 5 jun., 2012.

JULIA, Dominique. A cultura escolar como objeto histórico. Revista Brasileira de História da Educação, Campinas: SBHE, n. 1, 2001, p.10-46.

KUNER, Udo Ingo. Tempo de guerra perspectiva de paz. In: RENNER, Ivan; KOHL, Merlinde Piening; KUNER, Udo Ingo (org.). Raízes, ramos e frutos. Novo Hamburgo: Echo, 2011

LUCA, Tânia Regina. História dos, nos e por meio dos periódicos. In: BASSANEZI, Carla Pinsky. Fontes históricas. São Paulo Contexto, 2006, p. 111-153.

MAGALHÃS, Justino. Da cadeira ao banco: escola e modernização (séculos XVIII-XX). Lisboa: UI\&DCE, 2010.

MENESES, Maria Cristina. A escola e sua materialidade: o desafio do trabalho e a necessidade da interlocução. Pró-posições, Campinas, v. 16, n. 1, 2005, p. 13-17.

NÓVOA, António. A imprensa de educação e ensino. In. CATANI, Denice Barbara; BASTOS, Maria Helena Camara. Educação em revista: a imprensa periódica e a história da educação. São Paulo: Escrituras, 1997, p. 11-31.

OSORIO, Augustín Requejo. Conhecer para transformar. In: SEBARROJA, Jaume Carbonell et al. (orgs.). Pedagogias do século XX. Porto Alegre; Armed, 2003, p. 237-253.

QUEIROZ, Andréa Cristina de Barros. O pasquim: um jornal que só diz a verdade quando está sem imaginação (1969-1991). História \& Perspectiva. Uberlândia, n. 31, 2004, p. 229-252.

SOUSA, Rainer. Diretas já. Disponível em <http://www.brasilescola.com/historiab/diretaja.htm>. Acesso em: 5 jun., 2012.

SOUZA, Rosa Fátima de. História da cultura material escolar: um balanço inicial. In: BENTACOSTTA. Marcos Levy (org.). Culturas escolares, saberes e práticas educativas: itinerários históricos. São Paulo: Cortez, 2007, p. 163-189.

LUCIANE SGARBI S. GRAZZIOTIN é doutora em Educação e professora na Universidade do Vale do Rio dos Sinos. Pesquisa temas relacionados à Historia da 
Educação, sobretudo: relações de gênero e educação, memória oral e história da cultura material da escola. Vice-presidente da Associação Sul-Rio-Grandense de Pesquisadores em História da Educação.

Endereço: Rua Santo Antônio, 717/505 - 90220-011 - Porto Alegre - RS - Brasil.

E-mail: lusgarbi@terra.com.br.

JOANA FRANK é estudante de Pedagogia na Universidade do Vale do Rio dos Sinos. Atua como bolsista de iniciação científica no Programa de Pós-Graduação em Educação e desenvolve a atividade de auxiliar de educação infantil no Colégio Sinodal de São Leopoldo - RS.

Endereço: Rua Antunes Ribas, 53/501 - 93030-250 - São Leopoldo - RS- Brasil. E-mail: joana.frank@gmail.com.

Recebido em 25 de agosto de 2012.

Aceito em 27 de março de 2013. 